\title{
Experimental Evaluation of Refrigerant Mixtures as Substitutes for HFC134a
}

\author{
Dr. Deepak Paliwal \\ (Mechanical Engineering Department, S. V. Polytechnic College Bhopal, India)
}

\begin{abstract}
Refrigerant R134a base systems has higher GWP value that's why the conversion of same into ecofriendly system is the major concern for refrigeration industry. This investigation focuses on mixture ratio of pure hydrocarbon R290 and R600a used in 200 liter domestic refrigeration system by certain changes in mass ratio of refrigerants. In the present work, first of all the effect of mass ratio of HCM refrigerants on the performance of the system was investigated. HCM of R600a/R290 (60/40 by wt. \%) gave better performance than that of HCM R600a/R290 (70/30 by wt. \%), R600a/R290 (50/50 by wt. \%) and R134a.

The mass ratio of HCM (R600a/ R290) refrigerants was optimized for the performance parameter with respect to evaporating temperature. The COP of R600a/R290 (60/40 by wt. \%) mixture was higher than that of R600a/R290 (50/50 by wt. \%) by $21.9 \%$ and $17.6 \%$ at $-5^{\circ} \mathrm{C}$ and $5^{\circ} \mathrm{C}$ evaporative temperature respectively. COP decreased as propane mass fraction in HCM increased above $40 \%$.
\end{abstract}

Keywords: Refrigerant, R134a, Pull down, COP, R600a/R290, HCM.

\section{Introduction}

Refrigeration goes back to ancient times where storage of ice, evaporation of water, and other evaporative processes were prevailing. More specifically, refrigeration is that branch of science which deals with the process of decreasing and maintaining the temperature of any space or material below the temperature of the atmosphere[1]. According to ASHRAE, it is defined as the science of providing and maintaining temperature below that of surroundings [2]. For the past half century, CFCs have been used extensively in the refrigeration sector. (CFCs) and hydrochlorofluorocarbons (HCFCs) became the most dominant types of refrigerants due to their properties of non- corrosiveness, non-flammability, non-toxicity and non-irritability[3].

The problems occurred, when in 1974, Molina and Rowland, reported and published their ozone depletion hypothesis in which they claimed that the chlorine element catalytically destroyed the ozone layer in the stratosphere [4]. Since the advent of the Montreal Protocol, however, Refrigeration sector has been find out solution for ozone depleting substances. Alternative to CFCs refrigerants are HFC-152a, HFC-134a, MP66/39, HC-290/600a etc. These days, the concern for the greenhouse warming has never been greater. HFC-134a is non-flammable and has zero ozone depletion potential but serious GWP[5]. Thus, in 1997 the Kyoto Protocol was signed by many nations calling for the reduction in emissions of greenhouse gases including HFCs. There has been much resistance in adopting HFC134a for refrigeration equipment by some environmental groups. European countries are uses hydrocarbon in pure or mixed form on their refrigerator in early of 2000 . Hydrocarbon refrigerants are flammable[6]. They have zero ozone depletion potential and a greenhouse warming potential approaching zero. Many researchers have reported performance evaluation of hydrocarbon mixtures by both experimental and simulation methods [1-5]. India and China are the largest refrigerator demanding countries in the world, have been quite active in the application of hydrocarbons in domestic refrigerators. The assessment of alternative refrigerants is a difficult task[7]. Several criteria must be considered while selecting alternative refrigerants. The experimental work carried out in this area is also extensive. Many drop-in tests are being carried out to check the performance of replacement refrigerant in existing machines, designed for CFCs, HFCs and HCFCs[8].

\section{Literature survey}

Y. S. Lee et al.[9] did an experiment and tested Iso-butane in domestic refrigerator. The compressor input power varies from 230 and $300 \mathrm{~W}$, while the refrigerant charged was about $150 \mathrm{~g}$. It was found that the COP lie between $0.8-3.5$ in freezing application. This study focused only on the performance of a VCR system with R600a as the alternative refrigerants. B. Tashtoush et al. [10] conducted an experiment with the aim to analyze hydrocarbons (R600/R290/R134a) at various quantities in R12 domestic refrigerator. The results shows that Butane/Propane/R134a mixtures provide excellent performance parameters, such as COP of refrigerators, compression power, volumetric efficiency, condenser duty, compressor discharge pressure and temperature, relative to a $210 \mathrm{~g}$ charge of R12. S. Joseph Shekhar et al. [11] had performed experimental analysis on a 165 liter, CFC-12 based domestic refrigerator retrofitted with eco-friendly refrigerant mixture of HFC134a / HC290 /HC600a without changing the mineral oil. The system had been running successfully for more than 12 months, 
thus it was observed that the new mixture was compatible with mineral oil. The improvement in theoretical analysis of COP and actual COP were found out from 3 to $12 \%$ and 3 to $8 \%$, respectively. M. Fatouh et al. [12] had used LPG i.e. mixture of $60 \%$ propane and $40 \%$ commercial butane for drop-in replacement of HFC134a, in a single evaporator domestic refrigerator with a volume of $10 \mathrm{ft}^{3}$. Highest actual COP, lowest on-time ratio and lowered electric consumption were achieved in LPG refrigerator than that of R134a by $7.6 \%, 14.3 \%$ and $10.8 \%$, respectively. Hence, it can be concluded that the proposed LPG shown to be an appropriate and long-term alternative refrigerant to replace R134a in the existing refrigerator. K.Senthil Kumar et al. [13] experimentally tested HC mixture $(30 \% \mathrm{R} 290$ \& 70\%R123) and computationally replacing R12 in this work, to overcome the above said problem, in a refrigerant mixture R290 has been identified as suitable for combination with R123. . It is observed that the difference of pressure and temperature characteristics disappears as the R290 mass fraction is increased from $10 \%$ to $30 \%$ with R123 and the curve almost matches the R12 curve, which symbolized that mixture $7 / 3$ can exhibits similar properties and could be used as a substitute for CFC-12.

M. Mohanraj et al. [14] studied that domestic refrigerator uses HFC134a as refrigerant, due to its excellent thermodynamics and thermal- physical properties. But, HFC134a has high global warming potential (GWP) of 1300. This paper presents experimental results of an energy-efficient hydrocarbons (HC) mixture consisting of $45 \%$ HC290 and 55\% HC600a as a drop-in substitute for HFC134a as various mass charges of 40 $\mathrm{g}, 50 \mathrm{~g}, 70 \mathrm{~g}$ and $90 \mathrm{~g}$ in domestic refrigerators. The results practically showed that the $70 \mathrm{~g}$ mixture as barrier of COP, lower power consumption, lower pull-down time and lower discharging temperature than HFC134a. The miscibility of synthetic oil with HC refrigerant mixture was also found to be good. K. Mani et al. [15] done an experiment and analyzed that the performance study on a VCR system with the new refrigerant mixture R290/R600a as a drop-in replacement was with CFC-12 and HFC134a. Experimental results showed that the refrigerant effect of R290/R600a (68/32 by wt. \%) mixture was higher than that of R12 in the range of $19.9 \%$ to $50.1 \%$ at the lower evaporating temperature and in the range of 21.2 to $28.5 \%$ at the higher evaporating temperatures, respectively. COP of R290/R600a mixture increased from $3.9 \%$ to $25.1 \%$ at lower evaporating temperatures than that of R12 and COP of R290/R600a mixture increased from $11.8 \%$ to $17.6 \%$ at higher evaporating temperatures to than that of R12. The refrigerant R134a showed slightly lower coefficient of performance than R12. The R290/R600a (68/32 by wt. \%) mixture can be considered as a drop-in replacement refrigerant for CFC-12 and HFC134a refrigerants.

\section{Experimental setup}

An experimental set-up for vapor compression refrigeration system was designed to investigate the performance of R134a, R600a, R600a/R290 (70/30 by wt. \%), R600a/R290 (60/40 by wt \%) and R600a/R290 (50/50 by wt \%) mixture refrigerants. Fig.1 shows actual view of the experimental set-up and Fig. 2 shows line diagram. The system was a 200 liter domestic refrigerator ( with deep freezing capacity) that was originally designed for 150g R134a mass of refrigerant. It consists of two loops, the main loop consist of a compressor, a condenser, a filter-drier, a expansion device and a calorimeter, and second loop consisted of a evaporator instead of calorimeter with all other main equipments. Hermetically sealed reciprocating compressor recommended for R134a refrigerant of 200 liter refrigerator (with deep freezing capacity) was used in the system. A force convection air - cooled condenser was used. Capillary tube of 10 feet length, and 0.036 inches diameter was used as expansion device in the system. Refrigerating effects of the system calculated by a calorimeter connected in the main loop. It consisted of a cooling coil of 25 feet length and 5/16 inches diameter, temperature measuring device, a electric heater by motor and a stirrer rotted for maintaining equal temperature in the calorimeter. All these devices were properly placed in a insulated plastic container having 10 liter ethylene glycol. The calorimeter was fitted with an electric heater and a dimmerstat (attached with wattmeter) to calculate R.E. (heat gain by heater will be equal to heat removed by evaporator coil).

All these 9 thermocouples in the accuracy range of $-50{ }^{\circ} \mathrm{C}$ to $80^{\circ} \mathrm{C}$ with $\pm 0.1^{\circ} \mathrm{C}$ were fitted at inlet and outlet of all the major components. A drier was used after condenser to absorb moisture present in the refrigerant. In two pressure gauges, one is compound pressure gauge which is measured from -30 psi to 500 psi and one normal pressure gauge which is measured form -30 psi to 150 psi with \pm 1 psi accuracy fitted at compressor discharge and suction side, respectively. Compressor power consumption was measured by a wattmeter with an accuracy of $\pm 0.5 \%$. Energy consumption by the heating coils (inside calorimeter) was measured by a wattmeter with an accuracy of $\pm 0.5 \%$. Energy supply meter also used to calculate total energy consumption in $\mathrm{KW} / \mathrm{hr}$. 


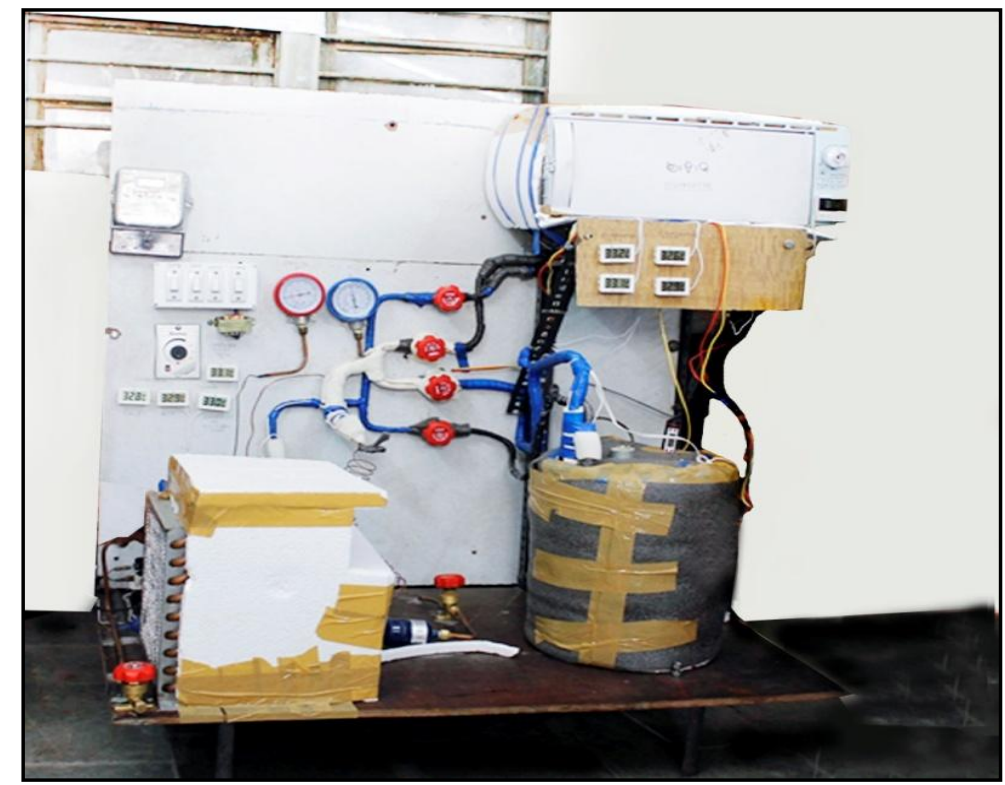

Figure 1: Actual view of experimental set-up for VCR system.

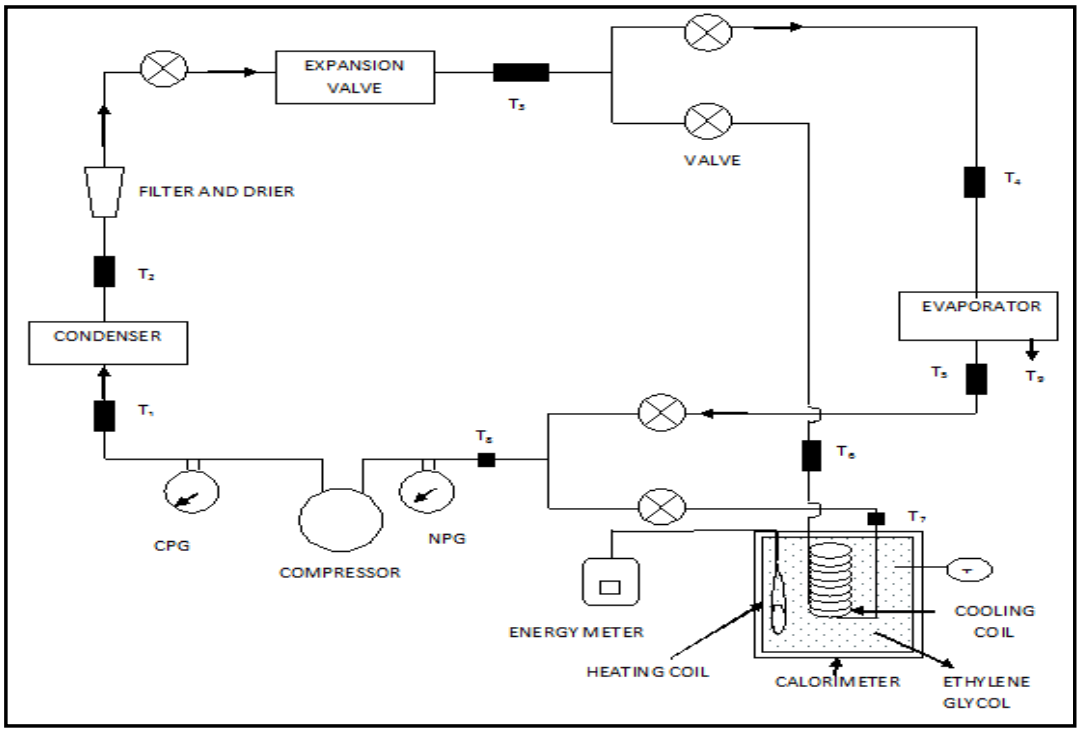

Figure 2: Line diagram of the experimental set-up for VCR system.

\section{Experimental procedure}

The system was evacuated up to the negative pressure -20 psi to eliminate impurities, moisture and other foreign materials present inside the system by using vacuum pump, which might affect the accuracy of the experimental set-up. Then the refrigerator was charged in different mass fraction with the help of electronic weight $\mathrm{m} / \mathrm{c}$ and charging valves. Initially we used $250 \mathrm{~g}$ R134a refrigerant to calculate values for base line test. After that $125 \mathrm{~g} \mathrm{HCM}$ in different mass fractions we used to find out best refrigerant for the system. In all, measurements are taken when the system reached steady state condition (calorimeter temperature was maintained for 10 minutes at measured value temperature with the help of dimmerstat).

Temperatures were recorded after every 10 minute interval in ${ }^{0} \mathrm{C}$ by 9 thermocouples, which are placed in all major equipments. Pressure at suction and discharge side of the compressor were also measured by two pressure gauges, after every 10 minute interval. To calculate pull down test system was cooled up from atmospheric temperature to desired temperature. R.E. at particular evaporating temperature was found by maintaining calorimeter, at that temperature with the help of heating device. In this process, wattmeter attached with calorimeter gave R.E. and wattmeter attached with compressor gave power consumption. The process was repeated for every refrigerants which were tested at all measured evaporating temperature. 


\section{Result and Discussion}

Experimental results obtained from pull down test with respect to time in minutes and performance parameters such as refrigerant effect, energy consumption, COP etc. with respect to evaporating temperature were analyzed for $125 \mathrm{~g} \mathrm{HCM} \mathrm{R600a/R290} \mathrm{(50/50} \mathrm{by} \mathrm{wt \% ),} \mathrm{R600a/R290} \mathrm{(60/40} \mathrm{by} \mathrm{wt} \mathrm{\% ),} \mathrm{R600a/R290} \mathrm{(70/30}$ by wt. \%) and compared these with $250 \mathrm{~g} \mathrm{R} 134 \mathrm{a}$ refrigerant to optimize mass ratio of the HCM refrigerant for the system. Experiments were conducted at ambient temperature of $30^{\circ} \mathrm{C}$.

1. Pull down characteristics - Fig. 3 shows the variation of calorimeter temperature with respect to time. The temperature of ethylene glycol (10 liter) was reduced from $20{ }^{\circ} \mathrm{C}$ for a period of 60 minute (continuous running test). The tests were conducted for different lengths of the capillary and refrigerants. In the entire range of operation minimum temperature was obtained for HCM 50/50. It is due to the fact that with increase in propane mass fraction, refrigerant mass flow rate increases M. Fatouh et al. [16]. It was observed that of continuous running test for 60 minutes on VCR system, the lowest temperature in calorimeter was measured to be $-5.8^{\circ} \mathrm{C}$ for refrigerant $125 \mathrm{~g}$ of R600a/R290 (50/50 by wt.\%). The second lowest temperature was observed to be -5.2 ${ }^{\circ} \mathrm{C}$ for $125 \mathrm{~g}$ of R600a/R290 (60/40 by wt. \%). Calorimeter temperature of $250 \mathrm{~g} \mathrm{R} 134 \mathrm{a}$ was found to be $-4.5^{\circ} \mathrm{C}$ in 60 minutes continuous running test. Results indicated that the cooling rate increased with the increase of mass percentage of R290 in refrigerant mixtures due to higher cooling capacity of R290 than other refrigerants. The nature of the graphs is similar as reported by Chao-Chieh Yu et al. [17].

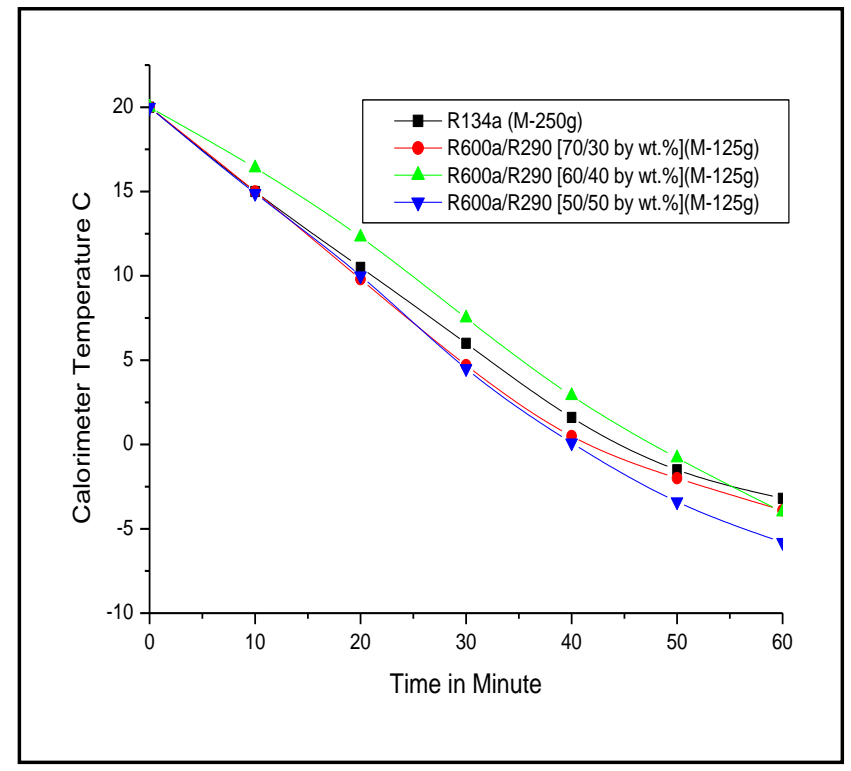

Fig. 3: Variations of calorimeter temperature with respect to the time (in minutes), at $30^{\circ} \mathrm{C}$ ambient temp.

(Continuous Running Test).

2. Refrigerating effect -Fig. 4 shows the effect of evaporating temperatures on the R. E. for the refrigerants 250 g R134, 125 g R600a/R290 (70/30wt.\%), 125 g R600a/R290 (60/40 by wt.\%) and 125 g R600a/R290 (50/50 by wt.\%), at the capillary length of 10 feet. It was observed that in the tested range of evaporating temperatures, the $\mathrm{R}$.E. increases with the increase in evaporating temperatures and was found to be maximum for the $125 \mathrm{~g}$ $\mathrm{R} 600 \mathrm{a} / \mathrm{R} 290$ 60/40. It is due to the fact that with increase in propane mass fraction refrigerant mass flow rate increases M. Fatouh et al. [16,38]. R. E. for HCM R600a/R290 (60/40 by wt. \%) was higher than that of R134a by $10 \%$ and $35.8 \%$, at $-5{ }^{\circ} \mathrm{C}$ and $5{ }^{\circ} \mathrm{C}$ evaporating temperatures, respectively. The percentage increase in R. E. for R600a/R290 (60/40 by wt. \%) was $13.7 \%$ and $7.7 \%$ than that of R600a/R290 (50/50 by wt. \%), at $-5{ }^{\circ} \mathrm{C}$ and $5{ }^{\circ} \mathrm{C}$ evaporating temperatures, respectively. The percentage increase in R. E. for R600a/R290 (60/40 by wt.\%) was $65 \%$ and $21.3 \%$ than that of R600a/R290 (70/30 by wt.\%), at $-5{ }^{\circ} \mathrm{C}$ and $5{ }^{\circ} \mathrm{C}$ evaporating temperatures, respectively. Refrigerating effect was found to be higher for R134a at lower evaporating temperature than that of HCM 70/30 and 50/50, because mass flow rate of refrigerant is directly proposal to R. E. The nature of the graphs was similar as reported by A. S. Dalkilic et al. [18]. 


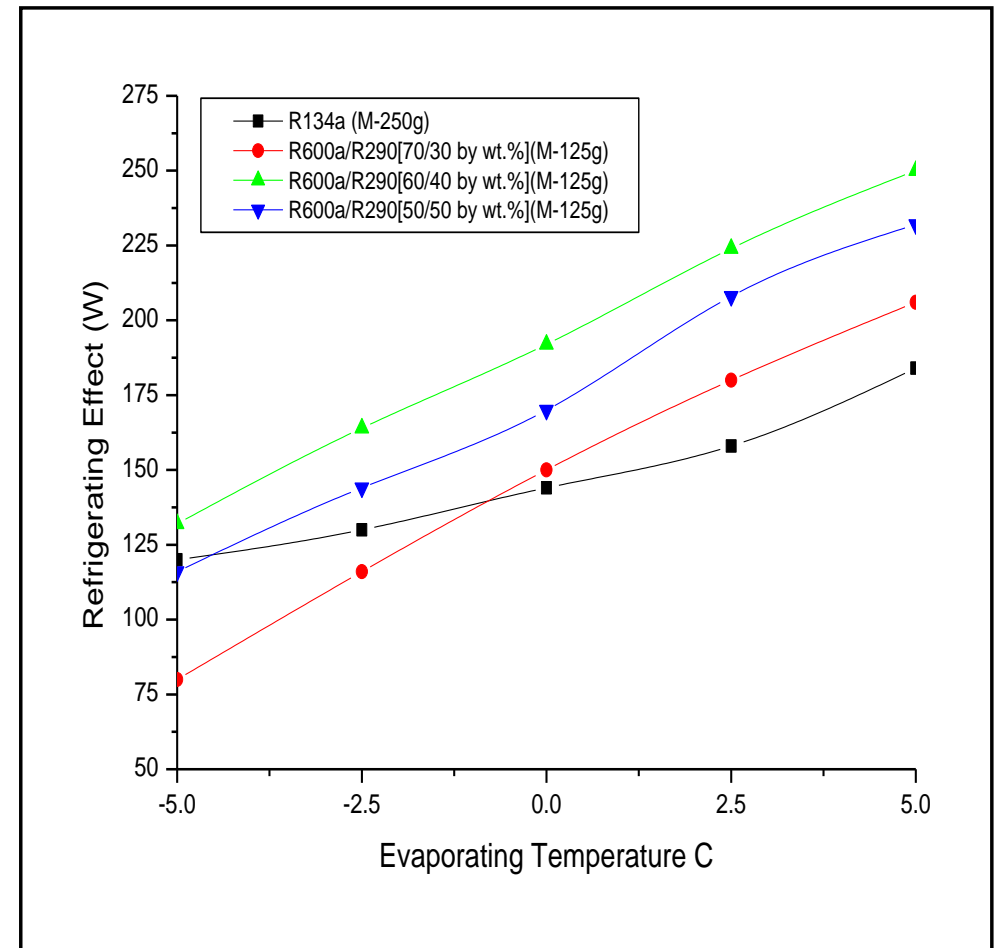

Fig. 4 : Variations of refrigerating effect with respect to the evaporating temperature, at $30^{\circ} \mathrm{C}$ ambient temperature.

3. Compressor energy consumption - Fig.5 shows the effect of evaporating temperatures on power consumption for the refrigerants $250 \mathrm{~g} \mathrm{R} 134,125 \mathrm{~g} \mathrm{R} 600 \mathrm{a} / \mathrm{R} 290$ (70/30 by wt.\%), $125 \mathrm{~g} \mathrm{R600a/R290} \mathrm{(60/40} \mathrm{by}$ wt.\%) and $125 \mathrm{~g} \mathrm{R600a/R290} \mathrm{(50/50} \mathrm{by} \mathrm{wt. \% ),} \mathrm{at} \mathrm{the} \mathrm{capillary} \mathrm{length} \mathrm{of} 10$ feet. It was observed that the power consumption was maximum for the R134a due to its higher mass flow rate. Power consumption was minimum for the mixture R600a/R290 (70 / $30 \mathrm{wt}$. \%) due to the lower mass percentage of R290 in HCM. It was evident that the energy consumption by the compressor increased slightly with change in the evaporating temperature. Energy consumption by the system with refrigerants R134a and R600a/R290 (50/50 by wt \%) were higher than that of R600a/R290 (60/40 by wt.\%) by $39.2 \%$ and $43.3 \%$, and $7.14 \%$ and $9.16 \%$, respectively at $-5^{\circ} \mathrm{Cand} 5^{\circ} \mathrm{C}$ evaporating temperatures. It is due to the fact that with increase in propane mass fraction, refrigerant mass flow rate increases. The mass flow rate is directly proportional to the compressor work.

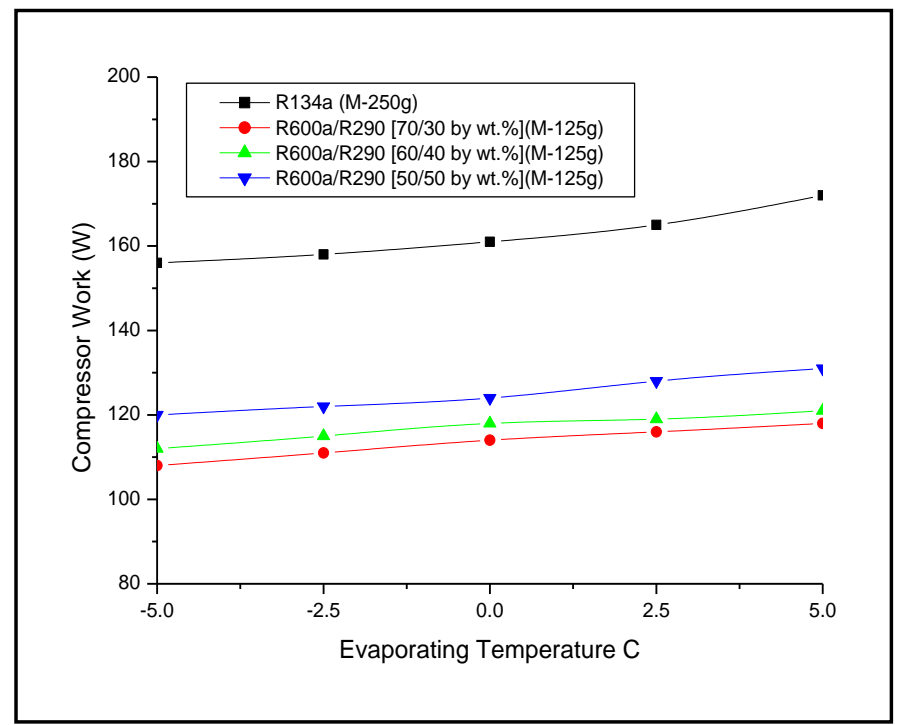

Fig. 5: Variations of energy consumption with respect to the evaporating temperature, at $30^{\circ} \mathrm{C}$ ambient temperature. 
4. Coefficient of performance (COP) -Fig.6 shows the effect of evaporating temperature on the COP for the refrigerants $250 \mathrm{~g} \mathrm{R} 134,125 \mathrm{~g} \mathrm{R} 600 \mathrm{a} / \mathrm{R} 290$ (70/30 by wt.\%), $125 \mathrm{~g} \mathrm{R} 600 \mathrm{a} / \mathrm{R} 290$ (60/40 by wt.\%) and $125 \mathrm{~g}$ $\mathrm{R} 600 \mathrm{a} / \mathrm{R} 290$ (50/50 by wt.\%). It was evident that the COP increases considerably with the increase of evaporating temperature except for R134. It was also observed that the COP was the highest for the refrigerant R600a/R290 (60/40 by wt.\%) than that of other refrigerants. It was also observed that the COP of R600/R290 (60/40 by wt \%) mixture was higher than that of R134a by $53.1 \%$ and $72.3 \%$ at $-5{ }^{\circ} \mathrm{C}$ and $5{ }^{\circ} \mathrm{C}$ evaporating temperatures, respectively. The COP of HCM R600/R290 (60/40 by wt \%) was higher than that of R600a/R290 (50/50 by wt. \%) by $21.9 \%$ and $17.6 \%$ at $-5{ }^{\circ} \mathrm{C}$ and $5{ }^{\circ} \mathrm{C}$ evaporating temperatures, respectively. The COP of HCM R600/R290 (60/40 by wt. \%) was higher than that of HCM R600a/R290 (70/30 by wt.) by 59.1\% and $19.3 \%$ at $-5{ }^{\circ} \mathrm{C}$ and $5{ }^{\circ} \mathrm{C}$ evaporating temperatures, respectively. It can be seen that the COP decreases as propane mass fraction in HCM increases above $40 \%$. The main reason behind this trend is the rate of change in specific work, which is higher than that of cooling effect.

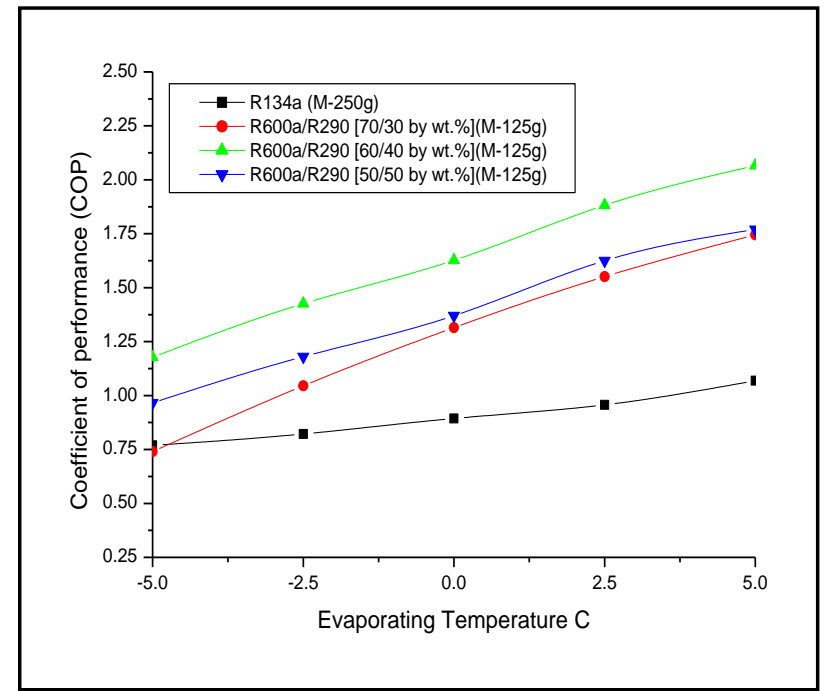

Fig. 6: Variations of coefficient of performance with respect to the evaporating temperature, at $30^{\circ} \mathrm{C}$ ambient temperature.

5. Pressure ratio $\left(\mathbf{P}_{1} / \mathbf{P}_{2}\right)$ - The desirable property of the refrigerant is that pressure should be low due to its minimize leakages past the compressor piston. The pressure ratio was maximum for the refrigerant R134a and was minimum for HCM R600a/R290 (70/30 by wt.\%) at the capillary length of 10 feet. The pressure ratio for $\mathrm{R} 600 \mathrm{a} / \mathrm{R} 290$ is minimum due to its lower mass flow rate.

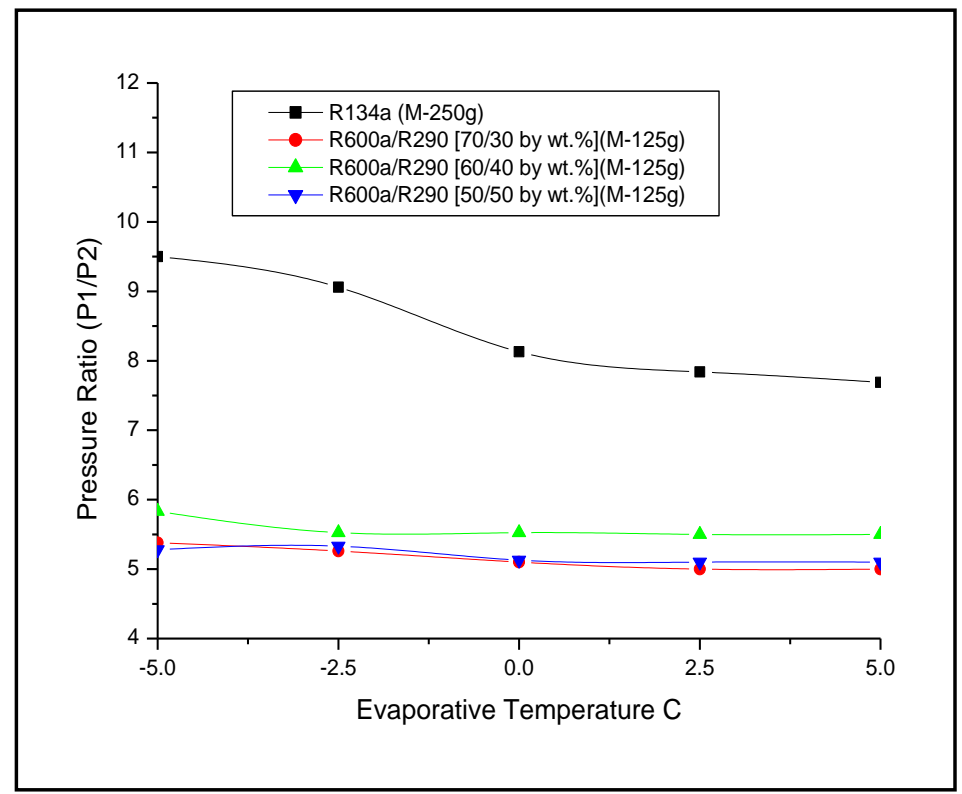

Fig. 7: Variations of compressor pressure ratio $\mathrm{P}_{1} / \mathrm{P}_{2}$ (Discharge / Suction). 
6. Compressor Discharge Temperature - Compressor Discharge Temperature always be higher for HFC134a refrigerant but you can see in graphs the value of discharge temperature was quit low for HCM because lower mass of refrigerants as well as better cooling tendency and lower vapor pressure of R600a in HCM than other tested refrigerants. This is also give advantage for consumption of lubricating oil also low for HCM.

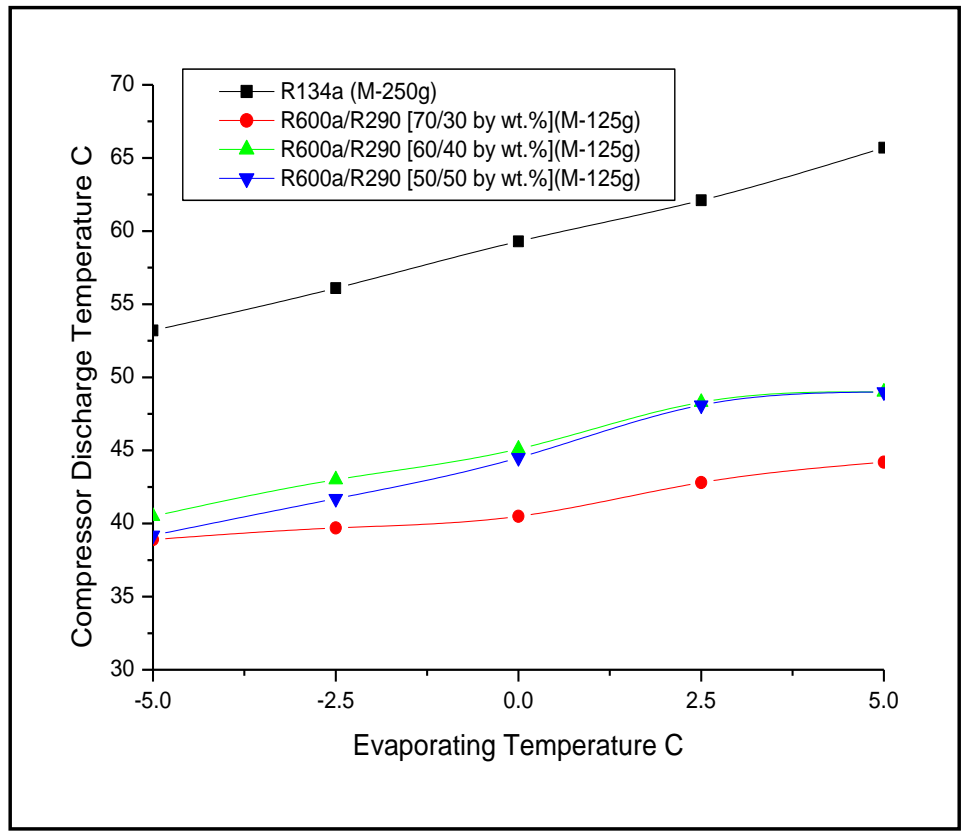

Fig. 8 : Variations of compressor discharge temperature with respect to the evaporating temperatures.

\section{Conclusion}

The lowest temperature in calorimeter was measured to be $-5.8{ }^{\circ} \mathrm{C}$ for the refrigerant of $125 \mathrm{~g}$ of $\mathrm{R} 600 \mathrm{a} / \mathrm{R} 290$ (50/50 by wt \%) and the second lowest temperature was obtained to be $-5.2{ }^{\circ} \mathrm{C}$ for $125 \mathrm{~g}$ of R600a/R290 (60/40 by wt. \%). R.E. of HCM refrigerant R600a/R290 (60/40 by wt. \%) was increased by 10\% and $35.8 \%$ than that of R134a, at $-5{ }^{\circ} \mathrm{C}$ and $5{ }^{\circ} \mathrm{C}$ evaporating temperatures, respectively. Percentage increase in R.E. for R600a/R290 (60/40 by wt. \%) was $13.7 \%$ and $7.7 \%$ than that of R600a/R290 (50/50 by wt. \%), at $-5^{\circ} \mathrm{C}$ and $5^{\circ} \mathrm{C}$ evaporating temperatures, respectively. Power consumption was maximum for R134a due to its higher mass flow rate. Power consumption was minimum for the mixture R600a/R290 (70/30 by wt. \%) due to the lower mass percentage of R290 present in that. Energy consumption for the refrigerants R134a and R600a/R290 (50/50 by wt. \%) was higher than that of R600a/R290 (60/40 by wt. \%) by $39.2 \%$ and $43.3 \%$, and $7.14 \%$ and $9.16 \%$, respectively at $-5^{\circ} \mathrm{C}$ and $5{ }^{\circ} \mathrm{C}$ evaporating temperatures. COP of HCM R600/R290 (60/40 by wt. \%) was higher than that of R134a by $53.1 \%$ and $72.3 \%$ at $-5^{\circ} \mathrm{C}$ and $5{ }^{\circ} \mathrm{C}$ evaporating temperatures, respectively. COP of HCM R600/R290 (60/40 by wt. \%) mixture was higher than that of R600a/R290 (50/50 by wt. \%) by $21.9 \%$ and $17.6 \%$ at $-5{ }^{\circ} \mathrm{C}$ and $5{ }^{\circ} \mathrm{C}$ evaporating temperatures, respectively. COP decreased as propane mass fraction in HCM increased above $40 \%$. The pressure ratio was the maximum for the refrigerant R134a and was in minimum for HCM R600a/R290 (70/30 by wt. \%) at the capillary length of 10 feet.

\section{References}

[1]. Roy J. Dossat, Principles of refrigeration, $4^{\text {th }}$ edition. Pearson education (Singapore) Pte. Ltd.,2003, New Delhi. Manohar Prasad, Refrigeration and air conditioning, $2^{\text {nd }}$ edition. New Age International publishers, 2010, New Delhi.

[2]. E. Halimic, D. Ross, B. Agnew, A. Anderson, and I. Potts, A comparison of the operating performance of alternative refrigerants. Applied Thermal Engineering 23 (12) (2003), 1441-1451.

[3]. M. Mohanraj. S. Jayaraj, C. Muraleedharan, Environment friendly alternatives to halogenated refrigerants- a review, Int. Journal Greenhouse Gas Control 3 (2009), 108-119.

[4]. M. Mohanraj. C. Muraleedharan, S Jayaraj, A review on recent developments in new refrigerant mixtures for vapor compression based refrigeration air conditioning and heat pump units Int. J Energy. Res 35 (8) (2011), 647-669.

[5]. Kyoto protocol, United Nations Framework Convention on Climate Change, United Nations, New York, USA, 1997.

[6]. Dr. S. Forbes Pearson, "New, Natural and Alternative Refrigerants", Star refrigeration Limited, 2013 Edinburgh.

[7]. D. Jung, Chong-Bo Kim, Kilhong Song, Byoungjin Park, Testing of propane / iso-butane mixture in domestic refrigerators, International Journal of Refrigeration, 23 (2000), 517-527.

[8]. Y.S. Lee, C. C. Su, Experimental studies of iso-butane (R600a) as the refrigerant in domestic refrigeration system. Applied Thermal Engineering 22 (2002), 507-519.

[9]. B. Tashtoush, Tahat, M., Shudeifat, M.A, Experimental study of new refrigerants mixture to replace R12 in domestic refrigerators, Applied Thermal Engineering 22 (2002), 495-506. 
[10]. S. J. Sekhar, D. Mohan Lal, and S. Renganarayanan, Improved energy efficiency for CFC domestic refrigerators retrofitted with ozone-friendly HFC134a/HC refrigerant mixture, International Journal of Thermal Sciences, 43 (3) (2004), 307-314.

[11]. M. Fatouh, M. kafafy, Experimental evaluation of a domestic refrigerator working with LPG, Applied Thermal Engineering 26 (2006), $1593-1603$.

[12]. K. Senthil Kumar, K. Rajagopal, Computational and experimental investigation of low ODP and low GWP HCFC-123 and HC-290 refrigerant mixture alternate to CFC-12, Energy Conversion and Management 48 (2007),3053-3062.

[13]. M. Mohanraj, S. Jayaraj and C. Muraleedharan, Improved energy efficiency for HFC 134a domestic refrigerator retrofitted with hydrocarbon mixture (HC 290 / HC 600a) as drop-in substitute, Energy for Sustainable Development 11,4 (2007), 29 - 33.

[14]. K. Mani, V. Selladurai, Experimental analysis of a new refrigerant mixture as drop in replacement for CFC12 and HFC 134a, International Journal of Thermal Sciences 47 (2008), 1490-1495.

[15]. M. Fatouh, M Kafary, Assessment of propane/commercial butane mixtures as possible alternatives to R134a in domestic refrigerators, Energy Conservation and Management 47 (2006), 2644-2658.

[16]. Chao-Chieh Yu, Tun-Ping Teng, Retrofit assessment of using hydrocarbon refrigerants, Applied Thermal Engineering 66 (2014), 507- 518 .

[17]. S. Dalkilic, S. Wongwises, A performance comparison of Vapor-compression refrigeration system using various alternative refrigerants, International Communications in Heat and Mass Transfer, 37(9),(2010) pp.1340-1349 